\title{
Animales de compañía y acción civil
}

Keywords: derecho; legislación; jurisprudencia; animal

La atención a los animales abandonados, cuyo número en España es -a tenor de los informes que la Fundación Affinity anualmente publica - altísimo, se gestiona habitualmente desde la compasión, el esfuerzo y la dedicación generosa del propio tiempo libre de muchos miles de personas, profesionales de las mas distintas procedencias, anónimos en la mayoría de los casos: voluntarios!. Cada día circulan por la red miles de correos electrónicos procedentes de Asociaciones Protectoras, Refugios, Grupos de amigos de los Animales, de nombres y situaciones estatutarias muy variadas [1] , que alertan al destinatario de tales mensajes, de casos de animales de compañía maltratados, abandonados, desnutridos, que necesitan atención veterinaria urgente, que buscan un nuevo hogar donde empezar una nueva vida y dejar atrás otra llena de penurias, que precisan de alguien que gestione una denuncia, que alertan de animales que pueden escapar de la muerte por eutanasia. A ese movimiento civil en pro de los animales, no se le da publicidad. Su labor queda, la mayoría de las veces, oculta a los ojos de gran parte de los ciudadanos de este país, pero es una labor eficaz, callada, resistente a cualquier adversidad.

Me estoy refiriendo a lo que se llama técnicamente el tercer sector, las organizaciones no gubernamentales (ONGs), que asumen, privadamente y sin ánimo de lucro, tareas destinadas a solucionar necesidades sociales por un compromiso personal con situaciones que, sin tales intervenciones quedarían sin solución. Precisamente con tal espíritu fueron aprobadas y se les dio una regulación [2] .

La propia sociedad, ágil y permeable a las necesidades cambiantes del día a día, se ha transformado en una mano amiga para los animales, a través de las ONGs. Algunas no reciben ese estatuto jurídico, pero participan del espíritu que explica su actividad, son asociaciones sin ánimo de lucro, civiles, en el mejor sentido del término civil, porque nacen de la iniciativa de los cives, los ciudadanos corrientes, de a pie.

El movimiento social a favor de los animales nació en los años 60 en Gran Bretaña. Al calor de la revolución que acortó las faldas de las mujeres, amplió el diámetro de las perneras de los pantalones, cambió para siempre la música pop con los Beatles y liberalizó la concepción social de las relaciones sexuales, los ciudadanos británicos ya muy sensibles, desde los inicios del S.XIX[ㅁ] , al sufrimiento animal, empezaron a organizarse en Asociaciones animalistas, proteccionistas, abolicionistas, luchadoras por el bienestar animal. No hay que olvidar que, precisamente pocos años antes, se había publicado un libro que contribuyó a sentar las bases del nuevo concepto jurídico de "bienestar animal” (Animal Welfare), me refiero a la aparición de “Animal Machines” [4], un libro que ponía al descubierto la triste realidad de los animales de producción, el confinamiento y la explotación de los animales destinados al consumo y su muerte cruel en mataderos donde lo que importaba era -como si de una olimpiada sangrienta se tratara, “citius, altius, fortius”-, más carne, más cantidad, más rápido, porque el mercado, así lo demandaba.

En efecto, Gran Bretaña había ido alimentado desde el S.XVIII, con intervenciones de grandes pensadores, de filósofos, de animalistas, el caldo de cultivo necesario para que las leyes reflejaran la sensibilidad social [ㄷ]. . La primera Asociación protectora de animales que aparece con este nombre en

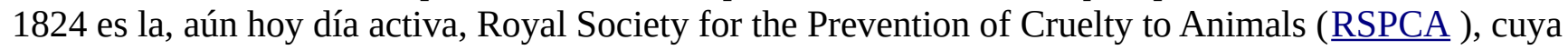
primera Presidenta fue la reina Victoria. La actual Queen Elisabeth, continúa -por tradición de la Casa Real británica- presidiendo y honrando con su patrocinio []]. 
Desde esta perspectiva, la realidad es que la normativa actual en España, reguladora de las subvenciones a toda la actividad social a favor de los animales, es claramente insuficiente y no cubre ni alienta el trabajo que muchas Asociaciones, Refugios, Grupos de Voluntarios, sobre todo los más modestos, realizan. De hecho, tienen que hacer un esfuerzo personal, a su propio costo, que raramente está reconocido y la mayoría de las veces tampoco recompensado con el agradecimiento público y el patrocinio a una labor muy eficaz e imprescindible.

Sería muy deseable que la normativa se adaptara a este sector (una parte importantísima del llamado tercer sector), que se publicitara su trabajo, que los grandes grupos económicos, como se hace en otros países, destinaran una parte de su presupuesto a subvenciones y ayudas a los ciudadanos que se asocian con el único deseo de ayudar a los animales. Su misión es muy simple y muy importante: darles voz, calor y afecto a los seres que tantas veces carecen de ello y que no pueden reclamarlo. Así comenzaríamos también a poner freno a los abandonos. Pero de este tema me ocuparé en breve.

La Editora

(1) Ver un mapa de localización

(2) Ley 38/2003 de 30 de noviembre, BOE número 276 de 18/11/2003, p. 40505 a 40532 (vid. norma Descargar ).

(3) La primera ley de Protección Animal se promulga en Gran Bretaña en 1802 (Bull Baiting Bill; vid. texto)

(4) R. HARRISON, Animal Machines: The New Factory Farming Industry (New York 1966)

(5) N.PEDERSEN, Overview of European Animal Welfare Laws: 2003 to Present Vid. (artículo completo)

(6) En otros países europeos, los miembros de las reales Casas no se pronuncian en favor de ninguna práctica, que lleve aparejada el trato cruel a los animales, es más, Su Majestad británica, refrendó -como constitucionalmente está previsto-, la desaparición de la muy tradicional y antigua práctica -imagen plástica del Reino Unido durante siglos- de la caza del zorro (Hunting Act 2004; vid. texto). 